\title{
Mentalne reprezentacije študentov pedagoških smeri do nadarjenih in njihovega izobraževanja ${ }^{\mathrm{I}}$
}

Nika Bedek, Maruša Loboda, Urška Žerak, Janez Vogrinc, Mojca Juriševič

\begin{abstract}
Uvod
Mentalne reprezentacije lahko opredelimo kot strukture, ki se oblikujejo v procesu ustvarjanja pomena pojmov v naših mislih s pomočjo jezika. Omogočajo nam organizacijo in klasifikacijo pojmov glede na kompleksne odnose med njimi ter predstavljajo povezovalni člen med pojmi in jezikom v določeni kulturi (Hall, 1997). Reprezentacije konstruiramo skozi učenje; izgrajujemo svoj mentalni svet v smislu pojmovnih zemljevidov in hkrati tudi jezik, s katerim se sporazumevamo na ravni osebnih pomenov med pripadniki iste skupine ali kulture, na splošno v življenju in v stroki. Različni kognitivni in afektivni dejavniki (npr. zaznave, pojmovne reorganizacije, stališča) vplivajo na mentalne reprezentacije v smislu njihovega mogočega spreminjanja, pa tudi različnih izkrivljanj (Carbon in Hesslinger, 2013). Mentalne reprezentacije učiteljev, ki opisujejo strokovne pojme, s katerimi učitelji dnevno operirajo besedno ali nebesedno, izhajajo iz njihovih izkušenj in rezultatov njihovih interakcij z okoljem (Sternberg, 2008).

Učitelji ključno prispevajo k izobraževalni izkušnji učencev (Swanson in Lord, 2013) in imajo na njihove dosežke pomembnejši vpliv kot kateri koli drugi dejavnik (Flynt in Brozo, 2009). Njihova stališča obsegajo osebne oz. subjektivne teorije poučevanja in učenja ter subjektivne teorije


o značilnostih učencev, ki preko učiteljevih ravnanj pomembno vplivajo na motivacijo in zadovoljstvo učencev pri določenem predmetu (Pajares, 1992). Szymanski et al. (2018) podarjajo, da imajo učitelji s svojimi stališči in vedenji med vsemi učenci največji vpliv na nadarjene, saj so oni najpogosteje tisti, ki jih prepoznajo za nadarjene in zanje predlagajo določene prilagoditve.

Pozitivna stališča učiteljev ne vplivajo le na poučevalno prakso, ampak posredno tudi na stališča in vedenja sošolcev (vrstnikov) nadarjenih ter spodbudno razredno klimo, ki zagotavlja optimalen razvoj nadarjenih učencev (Al Makhalid, 2012). Ozcan (2016) stališča prihodnjih učiteljev opisuje kot ključna za njihov nadaljnji razvoj in uspešnost poučevanja nadarjenih učencev. Avtor poudarja pomen učiteljevega dobrega poznavanja učnih značilnosti in potreb učencev ter razumevanje pomena diferenciranega in individualiziranega poučevanja za zadovoljevanje učnih potreb in spodbujanje učnih potencialov različnih učencev, med njimi tudi nadarjenih.

Raziskovalni izsledki kažejo, da imajo učitelji tako pozitivne kot tudi negativne mentalne reprezentacije o nadarjenih učencih (McCoach in Siegle, 2007). Poleg tega raziskovalci ugotavljajo, da so pri učiteljih prisotna stereotipna prepričanja o nadarjenih učencih, in sicer predvsem o tem, da imajo nadarjeni učenci visoke intelektualne sposobnosti in socialne, čustvene ali vedenjske težave (Matrić in Duh, 2019; Preckel et al., 2015). Schroth in Helfer (2009) navajata, da pri učiteljih prevladujejo tradicionalna pojmovanja nadarjenosti predvsem $\mathrm{v}$ smislu splošnih intelektualnih sposobnosti in visokih učnih dosežkov, pri tem pa so zanemarjeni nekateri specifični talenti nadarjenih učencev (npr. na področju umetnosti) in nadarjeni učenci, ki izkazujejo podpovprečne dosežke v šoli. Olthouse (2014) je $\mathrm{z}$ uporabo analize metafor ugotovila, da mentalne reprezentacije prihodnjih učiteljev o nadarjenih učencih odražajo zaznavo nadarjenosti v smislu hitrega pomnjenja dejstev in izkazanih dosežkov. Prihodnji učitelji nadarjenost dojemajo predvsem $\mathrm{v}$ splošnem smislu nadpovprečnosti na vseh področjih in izražajo pozitivno naravnane mentalne reprezentacije o nadarjenih učencih, iz česar bi bilo mogoče sklepati, da bodo ustrezno razumeli njihove izobraževalne potrebe in bodo naklonjeni specifičnim prilagoditvam (npr. akceleraciji in obogatitvenim dejavnostim). Na drugi strani ugotovitve kvantitativne študije mentalnih reprezentacij prihodnjih učiteljev kažejo (Bain et al., 2007), da študenti razumejo pojem nadarjenosti zelo 
široko ter izkazujejo egalitarne mentalne reprezentacije in pomanjkljivo razumevanje izobraževalnih potreb nadarjenih učencev.

Mentalne reprezentacije učiteljev o nadarjenosti učencev vplivajo na njihove odločitve o nominaciji potencialno nadarjenih učencev (Olthouse, 2014). Sternberg in Kaufman (2018) poudarjata, da je pri prepoznavanju nadarjenih učencev iz omenjenega razloga ne glede na teoretična izhodišča treba biti pozoren na naslednje: uporabo več raznolikih meritev, upoštevanje osebnostnih značilnosti, kot so angažiranost, ciljna usmerjenost in predanost, ter upoštevanje kontekstualnih dejavnikov, kot sta kultivacija nadarjenosti in socializacija nadarjenih.

Na osnovi povedanega je mogoče skleniti, da je mentalne reprezentacije učiteljev, kot izjemno vplivne kognicije za poučevanje in učenje učencev, mogoče raziskovati na različne načine, med drugim tudi s tehniko skupinskih asociacij AGA (angl. Associative Group Analysis; Szalay in Brent, 1967). Ta tehnika posredno meri zaznave, stališča in prepričanja posameznika s pomočjo prostih besednih asociacij; običajno uporablja za inferenčno raziskovanje medkulturnih razlik, pri čemer je v ospredju jezik kot komunikacijsko orodje preučevane skupine ljudi, s katerim ti izražajo svoje razmišljanje, doživljanje in vedenjske namere (Ross et al., 2005).

\section{Problem in cilj raziskave}

Stališča učiteljev do nadarjenih in njihovega izobraževanja so eden ključnih dejavnikov kakovostnega pedagoškega dela učiteljev z nadarjenimi učenci v šoli (Szymanski et al., 2018). Univerzitetno okolje, v katerem se izobražujejo prihodnji učitelji, zato predstavlja temeljni kontekst, v katerem lahko učitelji usvojijo znanje in izkušnje, ki prispevajo k razvoju strokovnega, na empiričnih dokazih temelječega pedagoškega pristopa. Da bi visokošolske ustanove, ki izobražujejo učitelje, to nalogo lahko kakovostno izvajale (npr. študente strokovno spodbujale, usmerjale in podpirale), je potrebno razumevanje o predznanju študentov; znanje o tem, kako študenti razmišljajo o obravnavani problematiki, kakšne so njihove osebne izkušnje, pojmovanja in stališča in kako jih je mogoče kultivirati v okviru vzgojno-izobraževalnega konteksta. Ob pregledu referenčne literature je mogoče ugotoviti, da je kljub svoji pomembnosti to področje še premalo raziskano. Cilj raziskave je bil zato ugotoviti, kako študenti - prihodnji učitelji - pred vstopom v pedagoško prakso razmišljajo o nadarjenih učencih in njihovem izobraževanju. Natančneje, zanimale so nas njihove mentalne reprezentacije o dveh teme- 
ljih pojmih s področja obravnave nadarjenih učencev v šoli, in sicer nadarjen učenec in izobraževanje nadarjenih.

\section{Raziskovalna metoda}

$\mathrm{V}$ raziskavi smo uporabili načela pedagoškega raziskovanja ter kombinacijo kvalitativnega in kvantitativnega pristopa. Udeleženci so bili študenti Pedagoške fakultete Univerze v Ljubljani v študijskem letu 2017/18, ki so bili namensko vzorčeni. To so bili redno vpisani študenti začetnega in zaključnega letnika na prvostopenjskih študijskih programih (Predšolska vzgoja, Razredni pouk, Dvopredmetni učitelj, Likovna pedagogika, Specialna in rehabilitacijska pedagogika Logopedija in Surdopedagogika in Socialna pedagogika). Sodelovalo je 480 študentov (65,7 \% osnovne populacije), od tega 284 študentov začetnega letnika (67,6 \% osnovne populacije) in 196 študentov zaključnega letnika (63,0 \% osnovne populacije). Večina študentov je bila ženskega spola $(92,5 \%)$.

Za namen raziskave smo uporabili tehniko AGA (Pergar Kuščer, 1998; Szalay in Brent, 1967), s katero smo kvalitativno preučili mentalne reprezentacije študentov oz. ugotavljali strukturo pomenov njihovih stališč o nadarjenih učencih in njihovem izobraževanju ter razlike med njimi glede letnik študija v ugotovljenih pomenskih strukturah.

Zbiranje podatkov je potekalo marca 2018. Študenti so tehniko AGA izvajali prostovoljno med predavanji po standardnih navodilih. Sledil je prepis podatkov. Asociacije smo analizirali po metodi AGA (več v Pergar Kuščer, 1998). Po ključu vsakega petega vprašalnika smo izbrali 50 preizkušancev iz vsake izmed dveh skupin. Iz nadaljnje obdelave smo izločili netipične asociacije, preostale smo točkovali z obteženimi frekvencami od 1 do 6.

\section{Tabela 15: Obtežitve asociacij}

\begin{tabular}{llllllllllll}
\hline Rang odgovora & 1 & 2 & 3 & 4 & 5 & 6 & 7 & 8 & 9 & 10 & Itn. \\
\hline Obtežitev & 6 & 5 & 4 & 3 & 3 & 3 & 3 & 2 & 2 & 1 & Itn.
\end{tabular}

Sledili so naslednji koraki: prepis asociacij posamezne skupine, združevanje glede na vsebinski pomen (sinonimi, metafore, besede v različnem številu, v različnih besednih vrstah itn.), poenotenje izrazov v obeh skupinah in seštevanje obteženih vrednosti. Nabor približno 50 asociacij smo po 
metodi odprtega kodiranja za vsak preučevanji pojem posebej razvrstili v 6 oz. 7 semantičnih kategorij.

\section{Rezultati z razlago}

Študenti začetnega in zaključnega letnika so več asociacij izrazili na pojem nadarjen učenec kot na pojem izobraževanje nadarjenih $\left(M_{z a c ̌ e t n i}=6,4\right.$ asociacij in $M_{z a k l j u c ̌ n i}=6,9$ asociacij oz. $M_{z a c ̌ e t n i}=5,4$ asociacij in $M_{z a k l j u c ̌ n i}=5,9$ asociacij). Pri obeh pojmih so bili po količini asociacij v prednosti študenti začetnega letnika (52 \% vseh asociacij pri prvem in 52,5\% vseh asociacij pri drugem pojmu). Povprečno število asociacij na posameznega študenta je bilo 6,15 asociacij, kar je nekoliko manj kot predvideva Pečjak (1994, v Pergar Kuščer, 1996), po katerem naj bi respondent v povprečju v eni minuti napisal sedem asociacij.

\section{Analiza semantičnih kategorij na osnovi asociacij študentov na pojem nadarjen učenec}

V obeh skupinah (Slika 9) največji delež pomenskega prostora zajema $k a$ tegorija A: konceptualizacija nadarjenosti $\left(f \%_{\text {začetni }}=34, f \%_{\text {zaključni }}=34\right)$, npr. pameten in nadpovprečen, $\mathrm{v}$ kateri sta profila primerjanih skupin podobna. Sledita kategorija B: področja nadarjenosti $\left(f \%_{z a c ̌ t n i}=17, f \%_{\text {zaključni }}=29\right)$, npr. učna uspešnost in umetnost, $v$ katero so večji delež asociacij prispevali študenti zaključnega letnika in kategorija C: učnomotivacijske lastnos$t i\left(f \%_{z a \check{c} t \text { tni }}=23, f \%_{\text {zaključni }}=16\right)$, npr. vedoželjen in marljiv, kjer so v prednosti študenti začetnega letnika Manjše, relativno enakomerno porazdeljene deleže v pomenskem prostoru zavzemajo naslednje kategorije: kategorija $D$ : kognitivne lastnosti $\left(f \%_{\text {začetni }}=15, f \%_{\text {zaključni }}=14\right)$., npr. divergentno razmišlja, ustvarjalen, kategorija E: socialno-emocionalne lastnosti $\left(f \%_{\text {začetni }}=7, f \%_{\text {zak- }}\right.$ liučni $=4$ )., npr. socialno spreten, asocialen in kategorija F: vidik družbe (f\%$z_{\text {začetni }}=4, f \%_{\text {zaključni }}=3$ )., npr. kritika identifikacije, izkoriščanje ugodnosti, ki jih prinaša status nadarjenega učenca. Višjo vsoto obteženih frekvenc predstavljajo asociacije študentov začetnega letnika $\left(\sum_{z a c ̌ e t n i}=1053\right.$ asociacij, $\Sigma_{z a k l j u c ̌ n i}=880$ asociacij).

Pomen pojma nadarjen učenec znotraj semantičnih skupin (A) konceptualizacija nadarjenosti in (B) področja nadarjenosti delno potrdi strokovno podprto razumevanje pojma nadarjenosti oz. nadarjenega učenca med študenti, kot je opredeljen v Beli knjigi o vzgoji in izobraževanju 2011 (Juriševič, 2011) in v prvem delu opredelitve nadarjenih učencev iz Zako- 


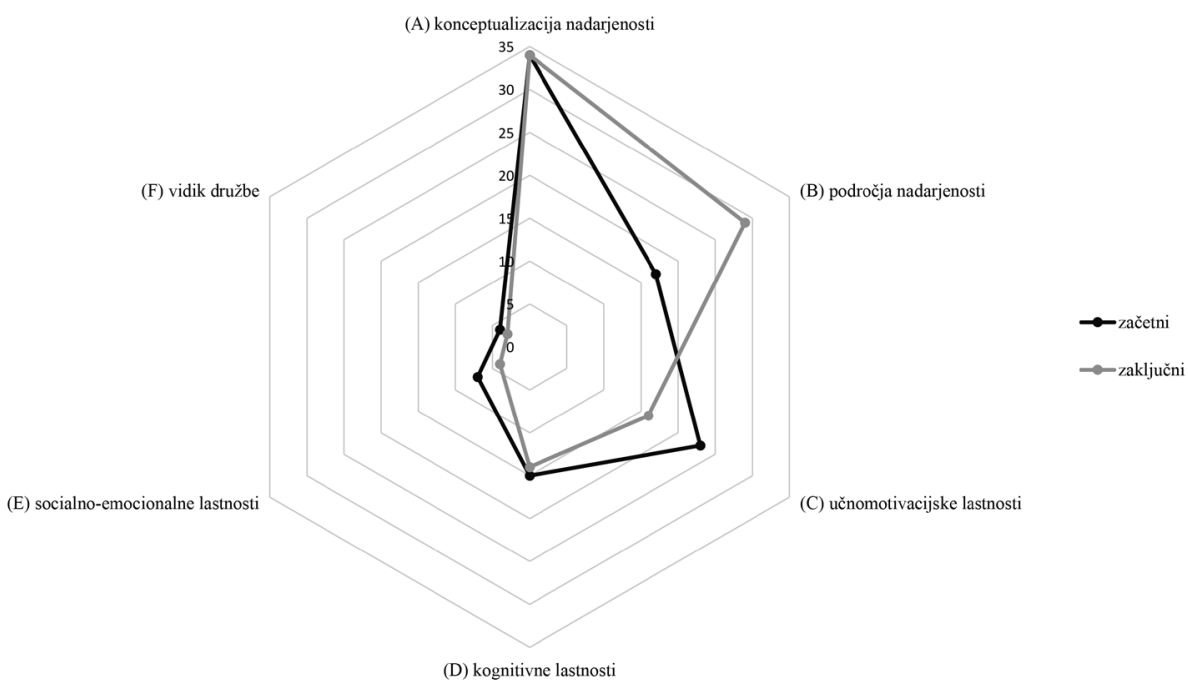

\section{Slika 9: Semantične kategorije za pojem nadarjen učenec}

na o osnovni šoli. Ta pravi, da so nadarjeni učenci »/.../ učenci, ki izkazujejo visoko nadpovprečne sposobnosti mišljenja ali izjemne dosežke na posameznih učnih področjih, v umetnosti ali športu./.../« (ZOsn, 11. člen). Mentalne reprezentacije študentov, skladno s šolsko kulturo, ki sprejema nadarjenost le na določenih področjih, in prevladujočimi stereotipi o akademsko nadarjenih učencih (IEA, 2018), postavljajo tudi v našem vzorcu nadarjenega učenca predvsem $\mathrm{v}$ šolsko okolje oz. izpostavljajo učno področje (izstopa matematika), ki mu sledi umetnost, medtem ko so denimo področje športa, $v$ smislu izjemnih psihomotoričnih sposobnosti, študenti le redko navedli kot asociacijo na dani pojem. O podobnih ugotovitvah poročajo tudi tuji raziskovalci (Olthouse, 2014; Schroth in Helfer, 2009), ki opozarjajo na pomen ustreznega razumevanja in pojmovanja nadarjenosti pri (prihodnjih) učiteljih, saj le-to ključno vpliva na njihovo poučevalno prakso. V zvezi s tem Sternberg in Kaufman (2018) poudarjata, da na konceptualizacijo nadarjenosti vplivajo tako eksplicitne kot implicitne teorije nadarjenosti, kar pomeni, da je pri izobraževanju učiteljev treba upoštevati doseženo strokovno znanje učiteljev in njihova bolj osebna oz. subjektivna pojmovanja o nadarjenosti in značilnostih nadarjenih učencev.

Kljub ugotovitvi, da so študenti kritični do množičnega prepoznavanja nadarjenih, ki je dejansko problem identifikacije v slovenski šoli (Juriševič, 2012a), njihove mentalne reprezentacije vključujejo tudi sorodne pojme, kot so talent in močna področja, kar kaže na precej nejasno poj- 
movanje nadarjenosti. Pri tem obstaja nevarnost, da to vodi v posplošeno prepričanje tipa »Vsak učenec je nadarjen.«. Zato je pomembno, da učitelji dosežejo natančnejše razumevanje pojma ter znajo razločiti med močnimi področji, ki jih imajo vsi učenci in nadarjenostjo, ki je opredeljena na osnovi kriterijev stroke in običajno pomeni izjemnost na določenem področju glede na večino vrstnikov (Juriševič, 2012a, 2018).

Iz vsebinske analize asociacij je mogoče opaziti tudi, da se semantične kategorije, vezane na lastnosti nadarjenega učenca, neposredno povezujejo s področji značilnosti nadarjenih učencev, ki jih prepoznava tudi širša stroka (Žagar et al., 1999) in sicer: miselno-spoznavno, učno-storilnostno, motivacijsko in socialno-čustveno področje; upoštevanje omenjenih psihosocialnih lastnosti pri identifikaciji nadarjenosti pomeni namreč večjo verjetnost, da je učenec nadarjen. Mentalne reprezentacije študentov v omenjenih kategorijah sovpadajo tudi z lastnostmi, ki jih med različnimi značilnostmi in vedenji učencev v razredu, slovenski učitelji najpogosteje prepoznavajo pri nadarjenih, in sicer samostojnost, zainteresiranost za šolsko delo, hitrost pri delu, vedoželjnost, zahtevnost, pozitivna predstava o sebi, prijaznost, motiviranost, pomoč drugim, uspešnost na akademskem področju itd. (Matrić in Duh, 2019).

Zanemarljiv delež v strukturi pomena pojma nadarjen učenec predstavljajo netipične značilnosti, ki jih pogosto najdemo pri učno neuspešnih nadarjenih učencih ali dvojno izjemnih učencih (Žagar et al., 1999). Kot ugotavljajo različni avtorji (Bianco in Leech, 2010; Neihart, 2018) je treba (prihodnje) učitelje senzibilizirati tudi za potrebe dvojno izjemnih učencev, kar predstavlja še poseben pedagoškopsihološki izziv na obravnavanem področju izobraževanja nadarjenih.

Skladno z empiričnimi ugotovitvami drugih raziskav (Martin et al., 2010; Neihart, 2002) so tudi izsledki te raziskave pokazali, da mentalne reprezentacije študentov nasprotujejo hipotezi disharmoničnega razvoja nadarjenih, ki predpostavlja izjemne sposobnosti in dosežke na šolskem oz. akademskem področju ter primanjkljaje in težave na psihosocialnem in emocionalnem področju (Baudson, 2016; Becker, 1978, v Matheis et al., 2019). To pomeni, da anketirani študenti nadarjene učence razumejo kot nadpovprečne oz. izjemne $\mathrm{v}$ primerjavi $\mathrm{z}$ večino vrstnikov na različnih področjih njihovega delovanja, ne le šolskem področju, kar bi bilo lahko prav tako odraz površinskega razumevanja pojma "nadarjen učenec«, saj poudarja drugi skrajni pol na kontinuumu harmoničnosti, ali pa dejansko poznavanje sodobnih raziskovalnih izsledkov, ki kažejo, da nadar- 


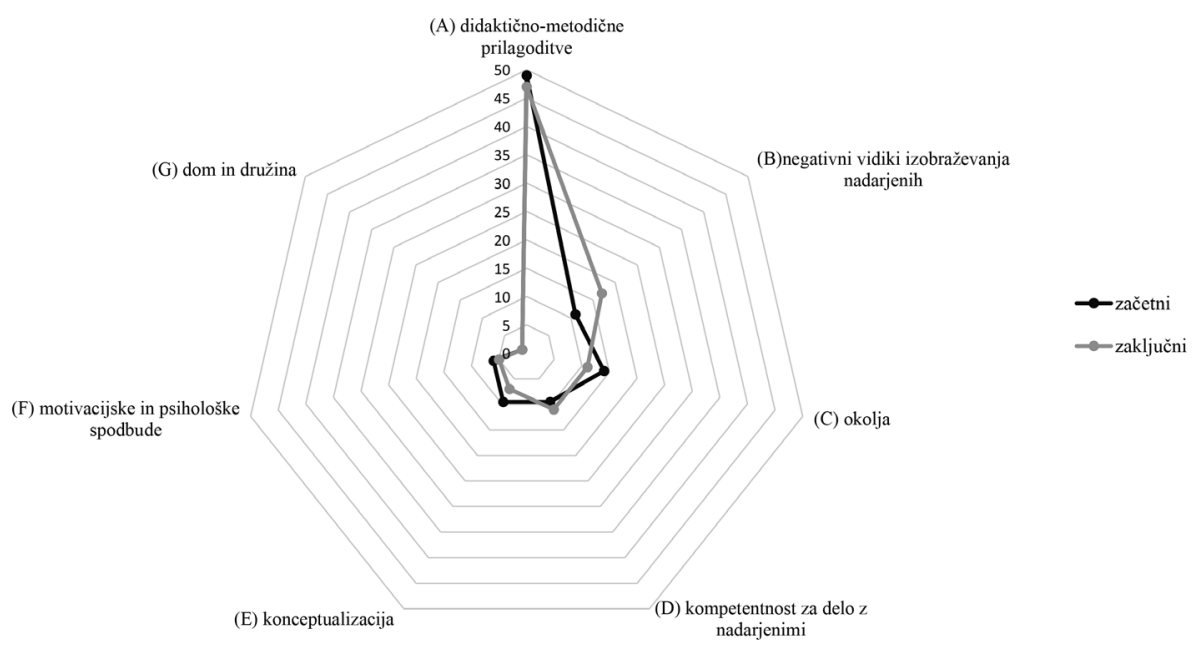

Slika ıo: Semantične kategorije za pojem izobraževanje nadarjenih

jeni učenci niso slabše osebnostno opremljeni kot njihovi vrstniki (Bergold et al., 2015; Freeman, 2010).

\section{Analiza semantičnih kategorij na osnovi asociacij študentov na pojem izobraževanje nadarjenih}

Obe primerjani skupini (Slika 10) zavzemata največji delež v semantični $k a-$ tegoriji A: didaktično-metodične prilagoditve $\left(f \%_{\text {začetni }}=49, f \%_{\text {zakljǔ̌ni }}=47\right)$, npr. dodatne naloge, dodatni pouk, zahtevnejše naloge. Sledi semantična kategorija B: negativni vidiki izobraževanja nadarjenih $\left(f \%_{\text {začetni }}=11, f \%_{\text {zak- }}\right.$ ljučni $=17)$, npr. kritika izvajanja v praksi, kritika identifikacije. Slednje nakazuje večjo kritičnost in zavedanje negativnih vidikov izobraževanja nadarjenih z višjim letnikom študija. Preostale semantične kategorije k strukturi pomena pojma prispevajo manjše, med študenti začetnega in zaključenega letnika relativno enakomerno porazdeljene deleže, in sicer kategorija C: okolja $\left(f \%_{\text {začetni }}=14, f \%_{\text {zaključni }}=11\right)$, npr. osnovna šola, obšolske dejavnosti, kategorija D: kompetentnost za delo $z$ nadarjenimi $\left(f \%_{\text {začetni }}=9,5, f \%_{\text {zaključni }}=\right.$ 12), npr. zahtevnejše delo učitelja, učiteljeva priprava, kategorija E: konceptualizacija nadarjenosti $\left(f \%_{\text {začetni }}=9,5, f \%_{\text {zaključni }}=7\right)$, npr. kultura in umetnost, testiranje, ter kategoriji F: motivacijske in psihološke spodbude ( $f \%_{\text {zǎetni }}$ $\left.=6, f \%_{\text {zakljǔ̌ni }}=5\right)$ in G: dom in družina $\left(f \%_{\text {začetni }}=1, f \%_{\text {zaključni }}=1\right)$, ki predstavljata najmanjši delež asociacij. Vsota vseh obteženih frekvenc je ponovno nekoliko višja pri študentih začetnega letnika $\left(\Sigma_{z a c ̌ e t n i}=1134, \Sigma_{z a k j j u c ̌ n i}=965\right)$. 
Asociacije na stimulativno besedno zvezo izobraževanje nadarjenih znotraj najbolj zastopane semantične kategorije didaktično-metodične prilagoditve potrdijo ponotranjeno zavedanje in če predpostavljamo, da asociacije sprožijo predhodne izkušnje (Sternberg, 20o8), do določene mere tudi implementacijo v praksi, drugega dela opredelitve nadarjenih učencev, in sicer »/.../Šola tem učencem zagotavlja ustrezne pogoje za vzgojo in izobraževanje, tako da jim prilagodi vsebine, metode in oblike dela ter jim omogoči vključitev v dodatni pouk, druge oblike individualne in skupinske pomoči ter druge oblike dela« (ZOsn, 11. člen). Prva kategorija semantično sovpada s karierno orientacijo študentov in s potrebami nadarjenih učencev (t. j. razvijanje močnih področij, individualiziran program, prilagoditve v kurikulumu, svetovanje itd.), ki jih kot pomembne pri nadarjenih učenih prepoznavajo slovenski učitelji tudi v že omenjeni raziskavi Matrić in Duh (2019). Čeprav študenti pedagoških smeri deklarativno izražajo naklonjenost do izobraževanja nadarjenih, opozarjajo na številne pomanjkljivosti implementacije v praksi. Kritičnost do sistemske ureditve in realnosti izvajanja specifičnih prilagoditev za nadarjene učence je se je pokazala tudi v raziskavi Loboda et. al. (2020), v kateri študenti poročajo o neizvajanju prilagoditev in dejavnosti za nadarjene učence $\mathrm{v}$ praksi ter so $\mathrm{z}$ vidika množičnega prepoznavanja kritični do procesa prepoznave nadarjenih, kar se sklada tudi $\mathrm{z}$ ugotovitvami ostalih slovenskih raziskovalcev (Boben, 2012; Juriševič, 2012a; Žagar, 2012).

\section{Zaključek}

Stališča prihodnjih učiteljev do izobraževanja nadarjenih so ključnega pomena za razvoj poučevanja nadarjenih učencev v prihodnosti, njihove mentalne reprezentacije pa nam omogočajo edinstven vpogled $\mathrm{v}$ njihovo razmišljanje o nadarjenih učencih. To ne predstavlja le zanimivih raziskovalnih izsledkov, temveč ima tudi aplikativno vrednost za izobraževalce učiteljev, da bi optimalno naravnali študijski proces v kultivacijo kognicij učiteljev (Huang, 2015).

Mentalne reprezentacije študentov v predstavljeni raziskavi odražajo splošno oz. površinsko razumevanje pojma nadarjen učenec, ter ga postavljajo predvsem v šolsko okolje oz. na akademsko področje, pri asociacijah pojma izobraževanje nadarjenih pa izstopata semantični kategoriji didaktično-metodičnih prilagoditev in kritika obstoječih praks dela $z$ nadarjenimi v vzgoji in izobraževanju. Zdi se, da gre za asociacije, ki izhajajo iz izkušenj študentov, predvsem na osnovi njihovega dosedanjega šolanja. $\mathrm{V}$ 
asociacijah je moč razbrati tudi naklonjenost do dodatnih izobraževanj na tem področju in zavedanje pomena strokovne kompetentnosti učitelja za poučevanje nadarjenih učencev.

Pridobljeni kvalitativni rezultati kažejo smernice za oblikovanje bolj specifičnih vsebin v študijskem procesu in razvoj strokovnih, na empiričnih dokazih temelječih pedagoških pristopov poučevanja nadarjenih, $\mathrm{v}$ smislu prožnih oblik učenja. Z razvojem ustreznih mentalnih reprezentacij o nadarjenosti pri prihodnjih učiteljih je namreč mogoče vplivati na oblikovanje njihovih pozitivno naravnanih stališč do izobraževanja nadarjenih in na povečanje njihove občutljivosti za razumevanje izobraževalnih potreb nadarjenih učencev znotraj širšega konteksta inkluzivnosti (Juriševič, 2012b).

Omejitve te raziskave oz. uporabe tehnike AGA avtorji prepoznavamo predvsem na jezikovnem področju oziroma pri izboru stimulativnih pojmov, saj avtorja tehnike Szalay in Brent (1967) priporočata uporabo ene besede, ne besedne zveze, kar verjetno vpliva na kvaliteto in kvantiteto besednih asociacij. Poleg tega je treba upoštevati tudi dejstvo, da na asociacije izbranih pojmov vpliva jezik ter širši sociokulturni kontekst. Zato bi bilo v prihodnje tehniko AGA smiselno uporabiti ob upoštevanju navedenih zaznanih izzivov in temeljiteje raziskati kognicije prihodnjih učiteljev.

\section{Literatura}

Al Makhalid, Khalid Abdu. »Primary teachers' attitudes and knowledge regarding gifted pupils and their education in the Kingdom of Saudi Arabia.« Doktorska disertacija, University of Manchester, School of Education, Manchester, 2012.

Bain, Sherry K., Stacy L. Bliss, Stephani M. Choate, and Katherine Sager Brown. »Serving children who are gifted: Perceptions of undergraduates planning to become teachers. "Journal for the Education of the Gifted 30, no. 4 (2007): 450-478.

Baudson, Tanja G. »The mad genius stereotype: Still alive and well.« Frontiers in Psychology 7 (2016): 1-9. doi: 10.3389/fpsyg.2016.00368.

Bergold, Sebastian, Linda Wirthwein, Detlef H. Rost, and Ricarda Steinmayr. "Are gifted adolescents more satisfied with their lives than their non-gifted peers? « Frontiers in Psychology 6 (2015): 1623. doi: 10.3389/fpsyg.2015.01623.

Bianco, Margarita in Nancy L. Leech »Twice-exceptional learners: Effects of teacher preparation and disability labels on gifted refferals." Teacher Education and Special Education 33 no. 4 (2010): 319-334. 
Boben, Dušica. »Smo psihologi (edini) kompetentni za identifikacijo nadarjenih?« V Posvetovanje Vloga psihologa v vzgoji in izobraževanju nadarjenih, urednici Mojca Juriševič in Božena Stritih, 57-76. Ljubljana: Pedagoška fakulteta Univerze v Ljubljani, 2012.

Carbon, Claus-Christian, and Vera Hesslinger. «Attitudes and cognitive distances: On the non-unitary and flexible nature of cognitive maps." $A d$ vances in Cognitive Psychology 9, no. 3 (2013): 121-129. doi: 10.2478/v10053oo8-0140-y.

Flynt, E. Sutton, in William G. Brozo. »It's all about the teacher." The Reading Teacher, 62 (2009): 536-538.

Freeman, Joan. Gifted lives: What happens when gifted children grow up. New York, NY: Routledge, 2010.

Hall, Stuart, ur. Representation: Cultural representations and signifying practices. Vol. 2. London, UK: Sage, 1997.

Huang, Jia-Li. »Cultivating teacher thinking: Ideas and practice. "Educational Research for Policy and Practice 14 (2015): 247-257. doi: https://doi. org/10.1007/s10671-015-9184-1.

IEA. Public attitudes towards gifted education. Pasadena, CA: Institute for Educational Advancement, 2018.

Juriševič, Mojca. »Inkluzivna edukacija nadarjenih učencev v kontekstu izobraževanja učiteljev.« V Inkluzija v sodobni šoli, urednika Dean Hozjan in Marko Strle, str. 253-268. Koper: Univerza na Primorskem, Znanstveno-raziskovalno središče, Univerzitetna založba Annales, 2012b.

Juriševič, Mojca. »Vzgoja in izobraževanje nadarjenih.« V Bela knjiga o vzgoji in izobraževanju v Republiki Sloveniji 2011, urednika Janez Krek in Mira Metljak, str. 329-345. Ljubljana: Zavod Republike Slovenije za šolstvo, 2011.

Juriševič, Mojca. »Zmorem in hočem več: nadarjen učenec pri pouku.« Fizika $v$ šoli, 23, no. 1 (2018): 2-8.

Juriševič, Mojca. Nadarjeni učenci v slovenski šoli. Ljubljana: Univerza v Ljubljani, Pedagoška fakulteta, 2012a.

Loboda, Maruša, Nika Bedek, Urška Žerak, Mojca Juriševič in Janez Vogrinc. »Stališča študentov pedagoških smeri do nadarjenih in njihovega izobraževanja." Didactica Slovenica Pedagoška obzorja 35, no. 1 (2020): 3-20.

Martin, Laurie, Rachel Burns in Matthias Schonlau. »Mental disorders among gifted and nongifted youth: A selected review of the epidemiologic literature.« Gifted Child Quarterly 54 (2010): 31-41. 
Matheis, Svenja, Lena Kristina Keller, Leonie Kronborg, Manfred Schmitt, and Franzis Preckel. "Do Stereotypes Strike Twice? Giftedness and Gender Stereotypes in Pre-Service Teachers' Beliefs about Student Characteristics in Australia." Asia-Pacific Journal of Teacher Education, 2019, 1-20.

Matrić, Maja in Matjaž Duh. »Teachers‘ perceptions of gifted, talented and EBD students.« Didactica Slovenica Pedagoška obzorja 34, no. 2 (2019): $67-81$.

McCoach, D. Betsy in Del Siegle. "What predicts teachers' attitudes toward the gifted." Gifted Child Quarterly 5, no. 3 (2007): 246-255. doi:10.1177/0016986207302719.

Neihart, Maureen. »Identifying and providing services to twice exceptional children."V Handbook of giftedness in children: Psychoeducational theory, research, and best practices, urednik Steven I. Pfeiffer, 115-137. New York, NY: Springer, 2008.

Neihart, Maureen, Sally M. Reis, Nancy M. Robinson in Sidney M. Moon. The social and emotional development of gifted children: What do we know? Waco, TX: The National Association for Gifted Children, 2002.

Ozcan, Deniz. »Predictions and attitudes towards giftedness and gifted education." International Journal of Educational Sciences 15, no. 1-2 (2016): 126133 .

Pajares, Frank. »Teachers' beliefs and educational research: Cleaning up a messy construct." Review of Educational Research 62, no. 3 (1992): 307332.

Pergar Kuščer, Marjanca. "Medkulturne razlike $v$ vrednotah in vrednotnih usmeritvah študentov. "Doktorska dizertacija, Univerza v Ljubljani, Filozofska fakulteta, Ljubljana, 1998.

Preckel, Franzis, Tanja Gabriele Baudson, Sabine Krolak-Schwerdt, and Sabine Glock. »Gifted and maladjusted? Implicit attitudes and automatic associations related to gifted children." American Educational Research Journal 52 (2015): 1160-1184. doi:10.3102/ooo2831215596413.

Ross, Alistair, Barbara Read, Marjanca Pergar Kuščer, Márta Fülöp, Cveta Pučko, Mihály Berkics, Mónika Sándor in Merryn Hutchings. »Teachers' constructions of citizenship and enterprise: Using associative group analysis with teachers in Hungary, Slovenia and England." The New Educational Review 7, 3-4 (2005): 111-139.

Sternberg, Robert J. Cognitive psychology. 5th ed. Belmont, CA: Wadsworth, 2008. 
Sternberg, Robert J. In Scott Barry Kaufman. »Theories and Conceptions of Giftedness." V Handbook of giftedness in children: Psychoeducational theory, research, and best practices, urednik Steven I. Pfeiffer, 29-47. New York, NY: Springer., 2018.

Swanson, Julie Dingle in E. Wayne Lord. »Harnessing and guiding the power of policy: Examples from one state's experiences. "Journal for the Education of the Gifted 36 (2013): 198-219.

Szalay, Lorand B. in Jack E. Brent. »The analysis of cultural meanings through free verbal associations. Journal of Social Psychology 72 (1967): 161-187.

Szymanski, Antonia, Laurie Croft in Brian Godor. »Determining attitudes toward ability: A new tool for new understanding." Journal of Advanced Academics 29, no. 1 (2018): 29-55.

Wilson, Janie H. »Predicting student attitudes and grades from perceptions of instructors' attitudes." Teaching of Psychology 33 (2006): 91-95.

ZOsn - Zakon o osnovni šoli. http://pisrs.si/Pis.web/pregledPredpisa?id=ZA$\mathrm{KO}_{448 .}$

Žagar, Drago, Jana Artač, Tanja Bezič, Mirt Nagy in Sonja Purgaj. Koncept. Odkrivanje in delo z nadarjenimi učenci v devetletni osnovni šoli. Ljubljana: Zavod Republike Slovenije za šolstvo, 1999.

Žagar, Drago. »Metodologija odkrivanja nadarjenih učencev v Sloveniji: zakaj tako in kaj spremeniti."V Posvetovanje Vloga psihologa v vzgoji in izobraževanju nadarjenih, urednici Mojca Juriševič in Božena Stritih, 19-26. Ljubljana: Pedagoška fakulteta Univerze v Ljubljani, 2012.

\section{Priloge}

Spodnji tabeli prikazujeta podrobnejšo primerjavo strukture pojmov nadarjen učenec (Tabela 16) in izobraževanje nadarjenih (Tabela 17) 
Tabela i6: AGA-nadarjen učenec - struktura semantičnih kategorij

\begin{tabular}{|c|c|c|c|c|}
\hline & \multicolumn{2}{|c|}{ Začetni letnik } & \multicolumn{2}{|c|}{ Zaključni letnik } \\
\hline & $f$ & $f \%$ & $f$ & $f \%$ \\
\hline Konceptualizacija nadarjenosti & 359 & $34 \%$ & 296 & $34 \%$ \\
\hline Pameten & 211 & & 119 & \\
\hline Nadpovprečen & 72 & & 78 & \\
\hline Sposoben & 43 & & 16 & \\
\hline Talent & 28 & & 9 & \\
\hline Močna področja & 3 & & 22 & \\
\hline Nadarjen & o & & 21 & \\
\hline Učenec s PP & 2 & & 11 & \\
\hline Dvojna izjemnost & o & & 12 & \\
\hline Gardner & o & & 8 & \\
\hline Področja nadarjenosti & 177 & $17 \%$ & 259 & $29 \%$ \\
\hline Učna uspešnost & 40 & & 84 & \\
\hline Umetnost & 76 & & 44 & \\
\hline Nadarjen na več področjih & 16 & & 57 & \\
\hline Matematika & 17 & & 24 & \\
\hline Nadarjen na enem področju & 14 & & 25 & \\
\hline Šport & 14 & & 15 & \\
\hline Nadarjen na enem ali več področjih & o & & 10 & \\
\hline Učnomotivacijske lastnosti & 238 & $23 \%$ & 143 & $16 \%$ \\
\hline Vedoželjen & 45 & & 41 & \\
\hline Marljiv & 48 & & 25 & \\
\hline Uspešen & 20 & & 26 & \\
\hline Sodeluje pri pouku & 44 & & $\mathrm{o}$ & \\
\hline Razgledan & 27 & & 6 & \\
\hline Aktiven & o & & 23 & \\
\hline Spreten & 19 & & o & \\
\hline Zdolgočasen & 8 & & 11 & \\
\hline Organiziran & 4 & & 11 & \\
\hline Nestereotipne lastnosti & 10 & & o & \\
\hline Samostojen & 10 & & o & \\
\hline Nemiren med poukom & 3 & & o & \\
\hline Kognitivne lastnosti & 157 & $15 \%$ & 125 & $14 \%$ \\
\hline Divergentno razmišlja & 53 & & 31 & \\
\hline Ustvarjalen & 35 & & 44 & \\
\hline Hitro dojema & 51 & & 16 & \\
\hline Logično sklepa & 11 & & 26 & \\
\hline Kritičen & 2 & & 8 & \\
\hline Igriv & 5 & & o & \\
\hline Socialno-emocionalne lastnosti & 77 & $7 \%$ & 34 & $4 \%$ \\
\hline Socialno spreten & 48 & & 19 & \\
\hline Asocialen & 10 & & 8 & \\
\hline
\end{tabular}




\begin{tabular}{lcccc} 
& \multicolumn{2}{c}{ Začetni letnik } & \multicolumn{2}{l}{ Zaključni letnik } \\
\hline & $f$ & $f \%$ & $f$ & $f \%$ \\
\hline Vodstven & 13 & & 0 & \\
\hline Perfekcionist & 0 & & 7 & \\
\hline Zadovoljen & 6 & $4 \%$ & 23 & $3 \%$ \\
\hline \multicolumn{1}{c}{ Vidik družbe } & 45 & & 0 & \\
\hline Kritika identifikacije & 22 & & \\
\hline Izkoriščanje ugodnosti & 11 & 11 & \\
\hline Piflar & 0 & 5 & 7 \\
\hline Spregledana nadarjenost & 6 & & 0 \\
\hline Stigmatizacija & 0 & & \\
\hline Pritisk družbe & 6 & & \\
\hline
\end{tabular}

Tabela 17: AGA-izobraževanje nadarjenih - struktura semantičnih kategorij

\begin{tabular}{|c|c|c|c|c|}
\hline & \multicolumn{2}{|c|}{ Začetni letnik } & \multicolumn{2}{|c|}{ Zaključni letnik } \\
\hline & $f$ & $f \%$ & $f$ & $f \%$ \\
\hline Didaktično-metodične prilagoditve & 554 & $49 \%$ & 458 & $47 \%$ \\
\hline Dodatne naloge & 167 & & 50 & \\
\hline Dodatni pouk & 92 & & 106 & \\
\hline Zahtevnejše naloge & 103 & & 48 & \\
\hline Prilagojeno delo & 35 & & 42 & \\
\hline Strategije dela & 17 & & 51 & \\
\hline Tekmovanja & 41 & & 19 & \\
\hline Diferenciacija in individualizacija & o & & 52 & \\
\hline Projektno delo & 23 & & 6 & \\
\hline Skupinsko delo & 23 & & 6 & \\
\hline Individualno delo & 21 & & 7 & \\
\hline Raznolikost dela & 21 & & 7 & \\
\hline IP & 11 & & 16 & \\
\hline Medpredmetno sodelovanje & o & & 18 & \\
\hline Problemske naloge & 14 & & 4 & \\
\hline Kreativne delavnice & 7 & & 10 & \\
\hline Akceleracija & o & & 16 & \\
\hline Negativni vidiki izobraževanja nadarjenih & 125 & $11 \%$ & 161 & $17 \%$ \\
\hline Kritika izvajanja v praksi & 66 & & 113 & \\
\hline Kritika identifikacije & 25 & & 21 & \\
\hline Kritika neenake obravnave & 21 & & o & \\
\hline Preobremenjenost nadarjenih & 8 & & 7 & \\
\hline Neusposobljenost učiteljev & 5 & & 9 & \\
\hline Pretirano poudarjanje & o & & 11 & \\
\hline Okolja & 161 & $14 \%$ & 104 & $11 \%$ \\
\hline Osnovna šola & 39 & & 51 & \\
\hline Obšolske dejavnosti & 51 & & 37 & \\
\hline
\end{tabular}




\begin{tabular}{|c|c|c|c|c|}
\hline & \multicolumn{2}{|c|}{ Začetni letnik } & \multicolumn{2}{|c|}{ Zaključni letnik } \\
\hline & $f$ & $f \%$ & $f$ & $f \%$ \\
\hline Tabori za nadarjene & 24 & & 11 & \\
\hline Študij & 24 & & 5 & \\
\hline Dodatna izobraževanja & 15 & & 0 & \\
\hline Srednja šola, gimnazija & 8 & & o & \\
\hline Kompetentnost za delo $\mathrm{z}$ nadarjenimi & 108 & $9,5 \%$ & 112 & $12 \%$ \\
\hline Zahtevnejše delo učitelja & 45 & & 21 & \\
\hline Učiteljeva priprava & 42 & & 15 & \\
\hline Izziv & 0 & & 30 & \\
\hline Usposabljanje učiteljev & o & & 26 & \\
\hline Lažje delo učitelja & 12 & & 4 & \\
\hline Šolska svetovalna služba & 9 & & 5 & \\
\hline Pedagoška fakulteta & o & & 11 & \\
\hline Konceptualizacija & 108 & $9,5 \%$ & 72 & $7 \%$ \\
\hline Kultura in umetnost & 45 & & o & \\
\hline Testiranje & 10 & & 28 & \\
\hline Socialno spreten & 13 & & 6 & \\
\hline Močna področja & o & & 18 & \\
\hline Pameten & 16 & & $\mathrm{o}$ & \\
\hline Samostojnost učenca & 5 & & 8 & \\
\hline Pomembnost & 10 & & 0 & \\
\hline Šolski predmeti & 1 & & 9 & \\
\hline Potencial & 3 & & 3 & \\
\hline Nadarjenost na enem področju & 5 & & o & \\
\hline Motivacijske in psihološke spodbude & 69 & $6 \%$ & 50 & $5 \%$ \\
\hline Spodbujanje in podpora & 37 & & 30 & \\
\hline Želje nadarjenih & 25 & & 3 & \\
\hline Višja pričakovanja & 7 & & 17 & \\
\hline Dom in družina & 9 & $1 \%$ & 8 & $1 \%$ \\
\hline Dom in družina & 9 & & o & \\
\hline Vloga staršev & o & & 8 & \\
\hline
\end{tabular}

